Waste and Resource Management Volume 169 Issue WR1

Waste-derived activated carbons for control of nitrogen oxides

Al-Rahbi, Nahil, Wu and Williams
Proceedings of the Institution of Civil Engineers

Waste and Resource Management 169 February 2016 Issue WR1

Pages 30-41 http://dx.doi.org/10.1680/jwarm.14.00021

Paper 1400021

Received 12/12/2014 Accepted 17/07/2015

Published online 16/09/2015

Keywords: environment/pollution/waste management \& disposal $\square$

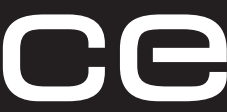

Institution of Civil Engineers

\title{
Waste-derived activated carbons for control of nitrogen oxides
}

Amal S.S. Al-Rahbi MSc

Research student, School of Chemical and Process Engineering, University of Leeds, Leeds, UK

Mohamad A. Nahil PhD

Research Fellow, School of Chemical and Process Engineering, University of Leeds, Leeds, UK
Chunfei Wu PhD

Research Fellow, School of Chemical and Process Engineering, University of Leeds, Leeds, UK

Paul T. Williams MSc, PhD, CEng, FEl, MCIWM

Professor, School of Chemical and Process Engineering, University of Leeds, Leeds, UK

Activated carbons were produced from waste and investigated for their efficiency for the removal of mono-nitrogen oxides $\left(\mathrm{NO}_{x}\right)$ in simulated flue gases at a low temperature. The wastes used were waste biomass (date seeds), processed municipal solid waste in the form of refuse-derived fuel and waste tyres. The morphology, porous texture and surface chemistry of the prepared activated carbons were evaluated by scanning electron microscopy, energydispersive X-ray spectrometry, nitrogen adsorption and Boehm titration, and were compared with several commercial activated carbons. The carbons were then investigated in terms of their use in adsorbing $\mathrm{NO}_{x}$ at a low temperature. The waste-derived activated carbons had $\mathrm{NO}_{x}$ adsorption efficiencies at $50^{\circ} \mathrm{C}$ which were between 50 and $70 \%$ of those achieved for the commercial activated carbons. Increasing the adsorption temperature from 25 to $100^{\circ} \mathrm{C}$ significantly reduced nitrogen oxide (NO) adsorption. It was also shown that the NO adsorption efficiency depends on the porous structure, particularly the presence of micropores in the activated carbon, but to a lesser extent on the surface area of the carbons and acid-base surface groups on the carbon surface.

\section{Introduction}

The combustion of solid fuels such as coal, biomass and wastes generates nitrogen oxides $\left(\mathrm{NO}_{x}\right)$ which cause environmental problems such as acid rain and smog. $\mathrm{NO}_{x}$ emissions in the flue gases are most commonly present as nitrogen oxide (NO; typically about $90 \%)$ and nitrogen dioxide $\left(\mathrm{NO}_{2}\right.$; typically about $10 \%) . \mathrm{NO}_{x}$ arise mainly from the nitrogen $\left(\mathrm{N}_{2}\right)$ in the fuel ('fuel $\mathrm{NO}_{x}$ ') and by direct combination of nitrogen and oxygen $\left(\mathrm{O}_{2}\right)$ present in the combustion air, which occurs more rapidly at high temperatures ('thermal $\mathrm{NO}_{x}$ '). In practice, thermal $\mathrm{NO}_{x}$ is formed almost exclusively at high flame temperatures.

Several technologies have been developed to control $\mathrm{NO}_{x}$ emissions (Belhachemi et al., 2014; Gómez García et al., 2005; Sousa et al., 2013). The addition of ammonia $\left(\mathrm{NH}_{3}\right.$, or urea) to the flue gases (selective non-catalytic reduction) can reduce $\mathrm{NO}_{x}$ by reaction to produce nitrogen and water, but is effective only over a narrow temperature range $\left(\sim 850-950^{\circ} \mathrm{C}\right)$. Selective catalytic reduction (SCR) uses a catalyst in the presence of added ammonia, which reproduces the ammonia reduction reaction but at a lower temperature $\left(\sim 250-400^{\circ} \mathrm{C}\right)$. The effectiveness of SCR for $\mathrm{NO}_{x}$ reduction can reach $85 \%$ and is a widely used technology (Belhachemi et al., 2014). However, the use of SCR has some drawbacks such as the difficulty of chemical handling and storage, and potential 'slippage' of ammonia, due to $<100 \%$ reaction (Gómez García et al., 2005; Sousa et al., 2013). Additionally, SCR is a costly method and the catalyst is prone to deactivation when sulfur dioxide $\left(\mathrm{SO}_{2}\right)$ is present in the flue gases. Therefore, there is interest in the development of low-cost and efficient techniques to control $\mathrm{NO}_{x}$ to meet the current stringent environmental regulations on emission limits. Of particular interest for $\mathrm{NO}_{x}$ control are low-temperature processes where the $\mathrm{NO}_{x}$ can be adsorbed after the gas scrubbing unit and where consequently low temperatures are encountered.

Removal of pollutants by adsorption is an effective method for the control of a range of pollutants. Although different adsorbents have been investigated including metal oxides, alumina, $\mathrm{FeOOH}$, silica and activated carbon (Azambre et al., 2009; Levasseur et al., 2012; Lopez et al., 2007), activated carbon has been used as an adsorbent for many pollutants such as heavy metals (particularly mercury), sulfur dioxide and $\mathrm{NO}_{x}$. The efficiency of activated carbon for the adsorption of pollutants is controlled by the degree of pore structure development 
and the chemical arrangement and the type and number of heteroatoms on the carbon surface (Kante et al., 2009; Lee et al., 2004).

Development of low-cost activated carbon adsorbents using waste materials has attracted the attention of many researchers as a route to producing valuable materials from wastes which also acts as an alternative to waste disposal. A variety of solid waste and biomass waste feedstocks have been used to produce activated carbon (Amalraj and Piu, 2013; Buah and Williams, 2010; El-Kady et al., 2013; Gil et al., 2014; Gundogdu et al., 2013; Gupta et al., 2014; Hajizadeh et al., 2011; Illingworth et al., 2012; Liu et al., 2014; Nahil and Williams, 2010). For example, activated carbons have been produced from municipal solid waste and used in the metal extraction industry (Buah and Williams, 2010); from waste tyres and used for dioxin adsorption from flue gases (Hajizadeh et al., 2011); also from waste tyres for use in the adsorption of phenolic compounds (Gupta et al., 2014); from waste fibreboard for use for copper (II) adsorption (Liu et al., 2014); from tannery wastes for use in the removal of dyes (Amalraj and Piu, 2013); from agricultural wastes from the removal of pesticides from water (El-Kady et al., 2013) and so on.

There have been several reports on the use of activated carbons to control $\mathrm{NO}_{x}$. The kinetics of $\mathrm{NO}_{x}$ removal by carbon of commercial origin has been studied by many researchers (Claudino et al., 2004; Klose and Rincón, 2007; Mochida et al., 1994; Shirahama et al., 2002; Teng and Suuberg, 1993; Zhang et al., 2008) and it has been concluded that the origin, the natural impurities in the feedstock, surface chemistry and the conditions used to prepare activated carbon are the main factors that can control its efficiency for $\mathrm{NO}_{x}$ reduction (Xu et al., 2003). Although there has been much research into $\mathrm{NO}_{x}$ control using activated carbons, the factors controlling the $\mathrm{NO}_{x}$ adsorption process are still not clear. The porous texture including the surface area and pore volume, the acidic and basic groups, the nitrogen content or nitrogen groups and the oxygen surface groups all can affect the NO removal by carbon. For example, Illan-Gomez et al. (1993) reported that no correlation was found between the NO reduction activity and carbon structure, and that activated carbons with different surface areas were all effective for NO reduction. The same conclusion was reported by other researchers, such as Guo et al. (2001), Neathery et al. (1997) and Ruiz Machado and Hall (1998). Neathery et al. (1997) found that the activated carbon with the lowest total pore volume and an intermediate surface area had the highest NO uptake capacity. In contrast, Rubio and Izquerido (2013) reported that the surface area and the carbon content were the main factors that influenced the removal efficiency of the activated carbon obtained from carbon-enriched coal fly ashes. Kaneko et al. (1988) claimed that the absorbability of activated carbon fibres in relation to $\mathrm{NO}$, ammonia and sulfur dioxide at low temperature increased with specific surface area. Mochida et al. (1994) reported that the main factor determining NO reduction activity was the nitrogen content of the samples. However, Illan-Gomez et al. (1993) found no correlation between the nitrogen content of activated carbons and the NO reduction activity. There is clearly uncertainty in the literature in relation to the influence of activated carbon characteristics on $\mathrm{NO}_{x}$ removal.

In this paper, the authors have produced activated carbons from low-cost waste materials in the form of biomass waste (date seeds) refuse-derived fuel (RDF) produced from the processing of municipal solid waste and waste tyres. The aim of this study was to examine the efficiency of these activated carbons for NO removal and to compare them with commercial carbons with varied porous texture and surface chemistry to determine the main carbon properties that influence NO adsorption. The NO adsorption was investigated at low temperatures, between 25 and $100^{\circ} \mathrm{C}$ to determine the effectiveness of NO control at low temperature.

\section{Experimental}

\subsection{Materials}

The activated carbon samples were designated as AC-D for the date seed biomass waste, AC-R for the activated carbon produced from RDF and AC-T for the carbons produced from waste tyres. Since municipal solid waste is a heterogeneous waste which has not been sorted and shredded, RDF was selected to represent the municipal solid waste with the elimination of recyclable materials such as metals and glass. The RDF sample was carefully prepared from $2 \mathrm{~kg}$ of RDF and was mixed, coned and quartered and further shredded to enhance homogeneity. The waste tyre sample was a shredded mixture of waste truck tyres. The sample was prepared by removing the steel followed by shredding and sieving. The date seeds were obtained from Oman and were crushed and sieved. All the samples were ground and sieved to a particle size of 1.7-3 mm. For comparison, four different commercial carbons (labelled C-AC1, C-AC2, C-AC3 and C-AC4) with different characteristics and porosity were used in this study and were obtained from Norit Ltd, the Netherlands. The carbons were of particle size $0 \cdot 15-3 \mathrm{~mm}$. The elemental analysis of the commercial and waste-derived activated carbons was carried out using a Carlo Erba Flash EA 1112 elemental analyser. A Shimadzu TGA-50H analyser was used to perform the proximate analysis of activated carbons. The metal content of the samples was determined using an Olympus Innovex X-5000 X-ray fluorescence (XRF) spectrometer. The device was equipped with an $\mathrm{Rh}$ source. The three waste materials were ashed in a furnace at $550^{\circ} \mathrm{C}$ for several hours. A lithium borate flux 
was added to the ash and heated to $900^{\circ} \mathrm{C}$ to form a melt. The melt was cooled down quickly to form a disc which was presented to the XRF spectrometer for analysis.

Table 1 shows the properties of the raw waste RDF, tyre and date seeds. The RDF had a significant ash content at $11.0 \mathrm{wt} \%$ consisting of mainly alumina-silicates and also a significant metal content, including heavy metals. The tyre also had a high ash content at $7 \cdot 1 \mathrm{wt} \%$, with zinc, as a prominent additive to the tyre manufacturing process, and also with the presence of other heavy metals and filler materials. The date seeds had

\begin{tabular}{lrrc}
\hline Proximate analysis: wt\% & RDF & Tyre & Date seeds \\
\hline Volatiles & 72.0 & 62.2 & 18.2 \\
Moisture & 5.0 & 1.3 & 7.5 \\
Ash & 11.0 & 7.1 & 4.0 \\
Fixed carbon & 13.0 & 29.4 & 69.9 \\
Minerals analysis: wt\% & & & \\
$\quad$ Zinc oxide & 0.06 & 2.95 & 0.01 \\
Silicon dioxide & 4.64 & 1.74 & 0.14 \\
Iron oxide & 0.36 & 0.40 & 0.03 \\
Calcium oxide & 1.86 & 0.24 & 0.21 \\
Potassium oxide & 0.28 & 0.07 & 1.98 \\
$\quad$ Aluminium oxide & 2.31 & 0.17 & 0.04 \\
$\quad$ Phosphorus pentoxide & 0.05 & 0.03 & 0.90 \\
Copper oxide & 0.01 & 0.06 & $<0.01$ \\
$\quad$ Magnesium oxide & 0.50 & 0.05 & 0.61
\end{tabular}

Table 1. Composition of raw waste materials the lowest ash content at $4 \cdot 0 \mathrm{wt} \%$ consisting of mainly nutrients such as calcium, potassium, magnesium and phosphorus.

\subsection{Preparation of activated carbons}

The activated carbons produced from the waste materials were prepared by pyrolysis followed by activation of the product char using steam. Pyrolysis of the date seeds, RDF and tyres was carried out in a fixed bed batch reactor, $250 \mathrm{~mm}$ in length by $30 \mathrm{~mm}$ internal diameter and was externally heated by an electric furnace (Figure 1(a)). The reactor was fully instrumented in terms of gas flow control, furnace temperature control and temperature monitoring throughout. The waste $(10 \mathrm{~g})$ was held in a sample crucible in the reactor and heated to a final temperature of $600^{\circ} \mathrm{C}$ at a heating rate of $10^{\circ} \mathrm{C} / \mathrm{min}$ and held at this final temperature for $1 \mathrm{~h}$. The recovery of char from the original raw material was 23.6, 31 and $37.5 \mathrm{wt} \%$ for the date seeds, RDF and waste tyres, respectively. Nitrogen was used as the carrier gas. A condenser system consisting of a water-cooled condenser and two solid carbon dioxide-cooled condensers was used to trap the condensable liquids. Non-condensable gases were collected in a Tedlar gas sample bag.

The chars recovered from the pyrolysis reactor were ground and sieved to $1 \cdot 5-2 \mathrm{~mm}$ and dried at a temperature of $105^{\circ} \mathrm{C}$ overnight and then activated in the pyrolysis reactor, which was adapted to incorporate steam injection by the addition of a steam generator at the inlet to activate the chars produced from the pyrolysis experiments (Figure 1(b)). During the activation process, the samples were heated at a heating rate of $20^{\circ} \mathrm{C} / \mathrm{min}$ to an activation temperature of $900^{\circ} \mathrm{C}$. Once the activation temperature was attained, the steam was introduced

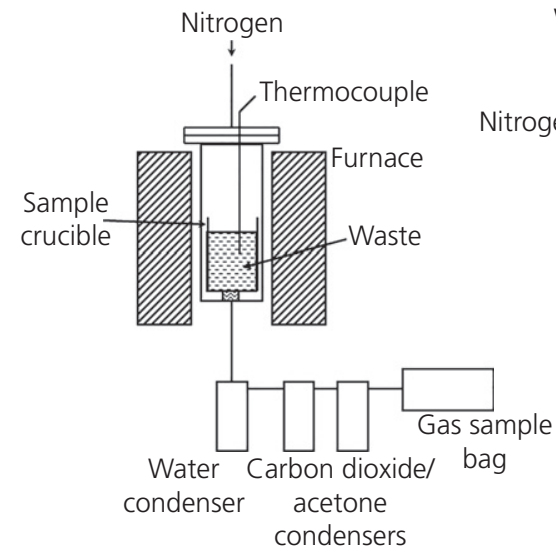

(a)

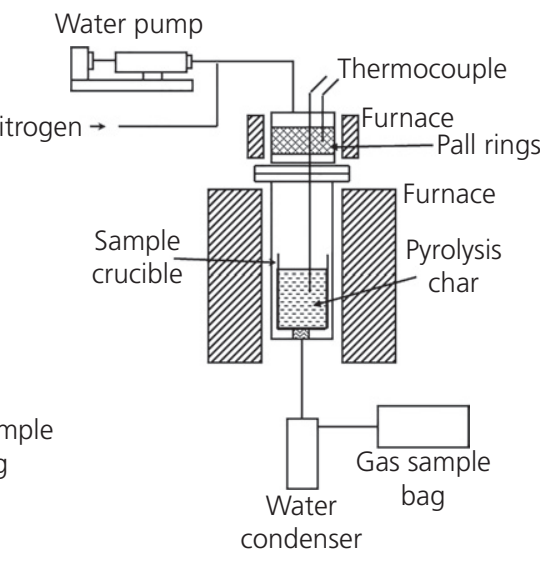

(b)

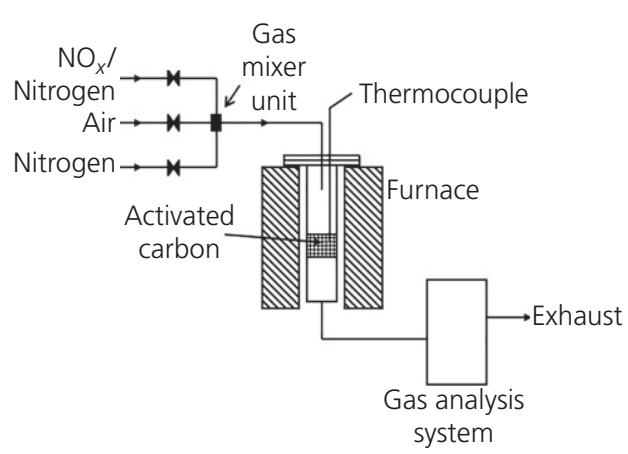

(c)

Figure 1. (a) Schematic diagram of the waste pyrolysis reactor;

(b) the char activation reactor; and (c) the gas adsorption reactor 
for a period of $3 \mathrm{~h}$. A Sage instrument model 255-2-syringe pump was used to inject deionised water into the steam generator which was maintained at $300^{\circ} \mathrm{C}$.

\section{3 $\mathrm{NO}_{x}$ adsorption reactor system}

The NO adsorption tests on the commercial and waste-derived activated carbons were conducted using a stainless steel fixed-bed reactor externally heated by an electric furnace (Figure 1(c)). The reactor system consisted of a gas mixing unit, the activated carbon- $\mathrm{NO}_{x}$ adsorption reactor and an online gas analysis system. Air, nitrogen and NO/nitrogen with an NO concentration of $1000 \mathrm{ppm}$ was supplied by B.O.C. Special Gases Ltd, UK. The gases were mixed together before entering the reactor in a gas mixing unit. The $\mathrm{NO}_{x}$ adsorption reactor was of $20 \mathrm{~cm}$ height and $2 \cdot 2$ internal diameter, with a $10 \mathrm{~cm}$ sample holder used to hold the activated carbon bed inside the reactor. The temperature of carbon was monitored with a thermocouple. The adsorption tests were conducted with a fixed activated carbon mass of $2.8 \mathrm{~g}$, which was previously treated under nitrogen at $500^{\circ} \mathrm{C}$ for $30 \mathrm{~min}$ in order to clean the surface oxides and desorb the adsorbed gases on the carbon surface (Claudino et al., 2004; Lopez et al., 2007). The bed depth was about $3 \mathrm{~cm}$ which gave $\sim 1.7 \mathrm{~s}$ gas residence time through the carbon bed. The adsorption was carried out for $2 \mathrm{~h}$ at different temperatures of 25,50 and $100^{\circ} \mathrm{C}$ and in the presence of a gas mixture of $5 \%$ oxygen and $800 \mathrm{ppm}$ NO, with a balance of nitrogen. The presence of oxygen in the gas mixture is essential, since it increases the adsorption of nitric oxide through the catalytic oxidation of $\mathrm{NO}$ to $\mathrm{NO}_{2}$, which results in an increase of $\mathrm{NO}$ adsorption due to the higher adsorption potential of $\mathrm{NO}_{2}$ (Klose and Rincón, 2007; Yang et al., 2000). In this work, experiments in the absence of oxygen showed that NO removal efficiency was only about $5 \%$; similar findings have been reported in the literature (DeGroot et al., 1991; Teng and Suuberg, 1993). The outlet gas was directed to a gas analyser system. The gas composition was recorded every minute using a gas analyser unit supplied by Horiba Instruments UK Ltd, and consisted of a Horiba VA-3000 chemiluminesence analyser for nitrogen oxide/ $\mathrm{NO}_{x}$ and a separate Horiba VA-3000 paramagnetic analyser for oxygen.

The NO removal efficiency of the used adsorbents was calculated according to Equation 1

1. $\mathrm{NO}$ removal efficiency $(\%)=\frac{\left(C_{\mathrm{NO}}^{0}-C_{\mathrm{NO}}\right)}{C_{\mathrm{NO}}^{0}} \times 100$

where $C_{\mathrm{NO}}^{0}$ and $C_{\mathrm{NO}}$ are the NO concentration before adsorption (at the outlet of the bypass) and after adsorption, respectively.

\subsection{Activated carbon characterisation}

The physical properties of activated carbons including BET (Brunauer, Emmett \& Teller) surface area and porosity of activated carbons were determined by the adsorption of nitrogen at $77 \mathrm{~K}$ using a Micromeritics TriStar 3000 apparatus, which measures the quantity of nitrogen adsorbed onto or desorbed from a solid sample at different equilibrium vapour pressures. Prior to the analysis, the samples $(0 \cdot 1 \mathrm{~g})$ were degassed under vacuum for $3 \mathrm{~h}$ at $300^{\circ} \mathrm{C}$. The micropore and mesopore volumes were determined by Dubinin-Radushkevich and Barret-JoynerHalenda methods, respectively. Pore size distribution was obtained by the density functional theory (DFT) method.

The Boehm titration method was used to determine the acidic and basic oxygen groups of the commercial and waste-derived activated carbons. The basic sites were determined by mixing $1 \mathrm{~g}$ of activated carbon with $50 \mathrm{ml}$ of $0.05 \mathrm{M}$ hydrochloric acid $(\mathrm{HCl})$ in a closed flask and shaken for $24 \mathrm{~h}$. The solution was then filtered. An aliquot of $5 \mathrm{ml}$ was taken and titrated with $0.05 \mathrm{M}$ sodium hydroxide $(\mathrm{NaOH})$. The acidic groups were determined by a similar procedure, where activated carbon was mixed with $0.05 \mathrm{M}$ sodium hydroxide and the titrant solution was $0 \cdot 05$ hydrochloric acid.

A SEM LEO 1530 high-resolution scanning electron microscope (SEM) coupled to an energy-dispersive X-ray spectroscope (EDXS) was used to characterise and examine the surface morphology of the prepared carbons with EDXS providing an indication of the metal content of the carbons.

\section{Results and discussion}

\subsection{Properties of the commercial and waste-derived activated carbons}

The proximate and ultimate analyses of the commercial activated carbons and the activated carbons produced from the waste materials are shown in Table 2. There are large differences in the ash content of the commercial carbons compared with the activated carbons produced from the waste materials, particularly the carbons produced from RDF and tyres. The mineral matter found in the original feedstock, becomes progressively concentrated through the process of pyrolysis, will reduce the mass of solid product through loss of volatiles as condensable liquids and non-condensable gases to produce the char. Additionally, during the activation process, the mineral matter is further concentrated as the carbon reacts with steam to produce gases, such as carbon dioxide, carbon monoxide, hydrogen, methane and so on as the char is activated (gasified). As can be observed from Table 2, the commercial carbons have high carbon contents (88-93\%). Among the used waste materials, date seeds showed the highest elemental carbon content $(74 \mathrm{wt} \%)$, fixed carbon $(83.9 \mathrm{wt} \%)$ and had a significant amount of nitrogen 


\begin{tabular}{|c|c|c|c|c|c|c|c|}
\hline \multirow[b]{2}{*}{ Sample } & \multicolumn{3}{|c|}{ Proximate analysis: wt\% } & \multicolumn{4}{|c|}{ Elemental analysis: wt\% } \\
\hline & Volatiles & Ash & Fixed carbon & Carbon & Hydrogen & Nitrogen & Oxygen $^{a}$ \\
\hline C-AC1 & $2 \cdot 5$ & $2 \cdot 4$ & $85 \cdot 6$ & $89 \cdot 9$ & $0 \cdot 3$ & 0.8 & $6 \cdot 0$ \\
\hline C-AC2 & $5 \cdot 1$ & $5 \cdot 0$ & $90 \cdot 9$ & $90 \cdot 8$ & $0 \cdot 3$ & 0.8 & $0 \cdot 3$ \\
\hline C-AC3 & $5 \cdot 5$ & $1 \cdot 3$ & $89 \cdot 3$ & $93 \cdot 5$ & 0.6 & 0.4 & $4 \cdot 1$ \\
\hline C-AC4 & $1 \cdot 7$ & $8 \cdot 2$ & $85 \cdot 6$ & $88 \cdot 0$ & $0 \cdot 3$ & 0.6 & $2 \cdot 0$ \\
\hline$A C-R$ (RDF) & $6 \cdot 1$ & $60 \cdot 9$ & $28 \cdot 9$ & $36 \cdot 4$ & 0.4 & $1 \cdot 5$ & 0.4 \\
\hline$A C-T$ (tyre) & $2 \cdot 8$ & $23 \cdot 9$ & $73 \cdot 3$ & $61 \cdot 1$ & $0 \cdot 2$ & $1 \cdot 4$ & $9 \cdot 3$ \\
\hline AC-D (biomass) & $4 \cdot 1$ & $10 \cdot 0$ & $83 \cdot 9$ & $74 \cdot 5$ & 0.6 & $2 \cdot 1$ & $12 \cdot 8$ \\
\hline
\end{tabular}

By difference

Table 2. Proximate and ultimate analysis of activated carbons

$(2 \cdot 10 \mathrm{wt} \%)$. These properties have been reported to accelerate NO adsorption by activated carbons (Zhang et al., 2008). The abundance of nitrogen content in AC-D could have a role in enhancing NO adsorption as reported by Rathore et al. (2010) in which the highest $\mathrm{NO}$ adsorption at room temperature was found with the sample containing the highest amount of nitrogen-containing groups. Bashkova and Bandosz (2009) concluded that a high $\mathrm{NO}_{2}$ adsorption was found with carbon containing quaternary nitrogen groups, which was ascribed to the presence of positive charge centres for the adsorption of $\mathrm{NO}_{2}$ and $\mathrm{NO}$, which can be further reduced to nitrogen or oxidised to nitrate. In addition, nitrogen-containing groups provide the basic properties to the carbon which was reported to enhance the interaction with acid molecules (Sousa et al., 2013).

Table 3 shows the analysis of activated carbons for their metal contents using XRF. There were clear differences between the carbons in terms of their ash composition. These differences may be attributed to the composition of the original precursor

\begin{tabular}{lccrc}
\hline Minerals analysis: wt\% & C-AC1 & C-AC2 & C-AC3 & C-AC4 \\
\hline Silicon dioxide & 0.15 & 0.07 & 0.04 & 1.07 \\
Iron oxide & 0.39 & 0.22 & 0.06 & 3.44 \\
Calcium oxide & 0.74 & 1.78 & 0.14 & 1.97 \\
Potassium oxide & 0.47 & 0.92 & 0.81 & 0.08 \\
Aluminium oxide & 0.02 & 0.01 & $<0.01$ & 0.52 \\
Phosphorus pentoxide & 0.47 & 0.10 & 0.05 & 0.08 \\
Magnesium oxide & 0.03 & 0.04 & 0.01 & 0.07 \\
Manganese oxide & 0.03 & 0.13 & 0.01 & 0.04
\end{tabular}

Table 3. Mineral composition of commercial activated carbons raw material (which was not known) or related to additives to the carbons during the preparation process.

The metal contents and surface morphology of the activated carbons produced from the waste materials were estimated from the SEM-EDXS analysis and are presented in Figure 2. The SEM images show that the type of activated carbon precursor has a strong influence on the development of porous texture of the resulting activated carbon. As shown in Figure 2, both the activated carbons derived from waste tyres and date seeds (AC-T and AC-D) present a smooth and a regular surface, while the RDF activated carbon (AC-R) shows a heterogeneous structure. The EDX spectra indicate the existence of a high percentage of calcium, sodium and other minerals with AC-R, while AC-T showed the presence of a high amount of zinc. The presence of abundant amounts of alkaline minerals in a sample cannot be assumed to give high reactivity for $\mathrm{NO}_{x}$, for example, Ahmed et al. (1993) reported a high nitrogen oxide adsorption activity with a sample that contained the lowest mineral content of alkaline metal oxides (calcium oxide, magnesium oxide and sodium oxide).

\subsection{Nitrogen oxide removal using commercial and waste-derived activated carbons}

The produced waste-derived activated carbons and the commercially obtained activated carbons were investigated for their $\mathrm{NO}$ adsorption characteristics with the $\mathrm{NO}_{x}$ adsorption reactor using a gas mixture of nitrogen oxide (800 ppm) and air ( $5 \mathrm{vol} \%$ oxygen) at an adsorption temperature of $50^{\circ} \mathrm{C}$. The NO removal efficiency curves for the commercial activated carbons and the waste-derived activated carbon are shown in Figures 3(a) and 3(b), respectively. There is an initial high adsorption of nitrogen oxide by the activated carbons, but the level of adsorption decreases before reaching a steady level of adsorption. The highest removal efficiency of 


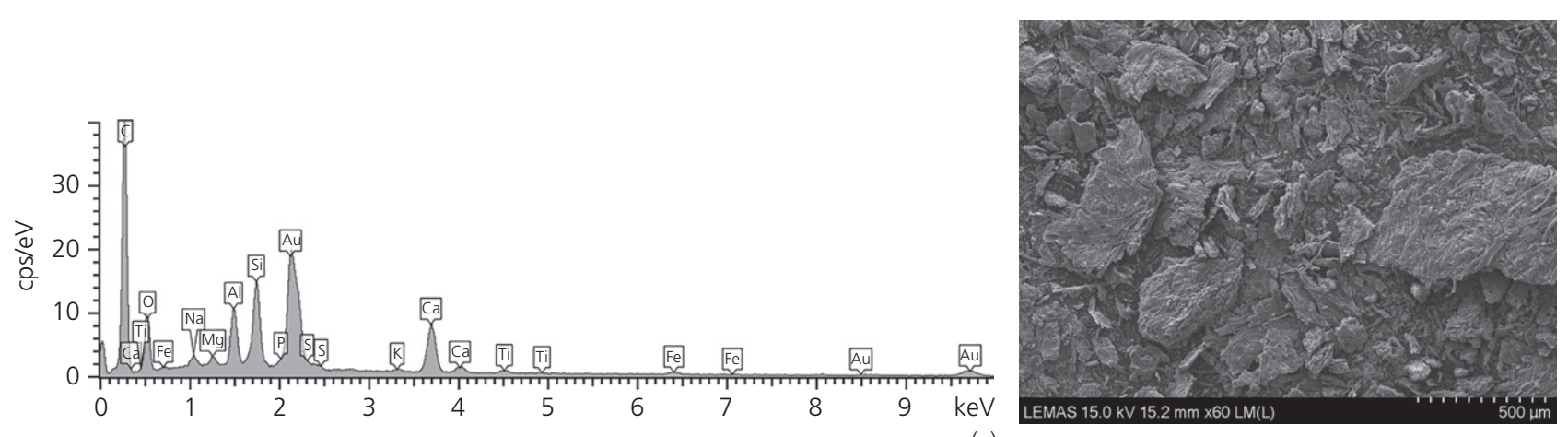

(a)
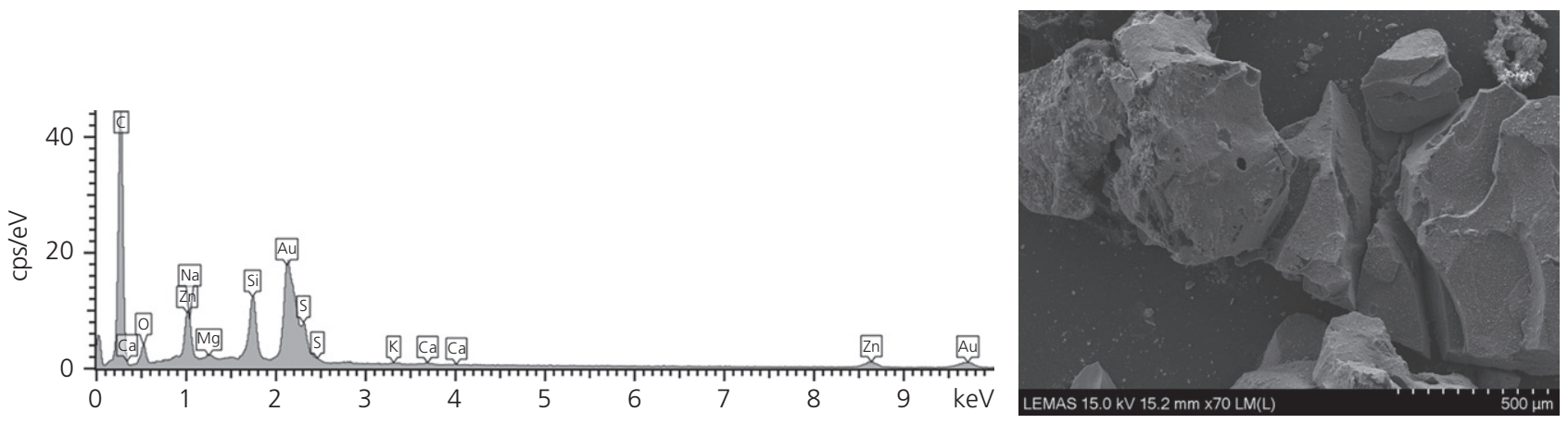

(b)
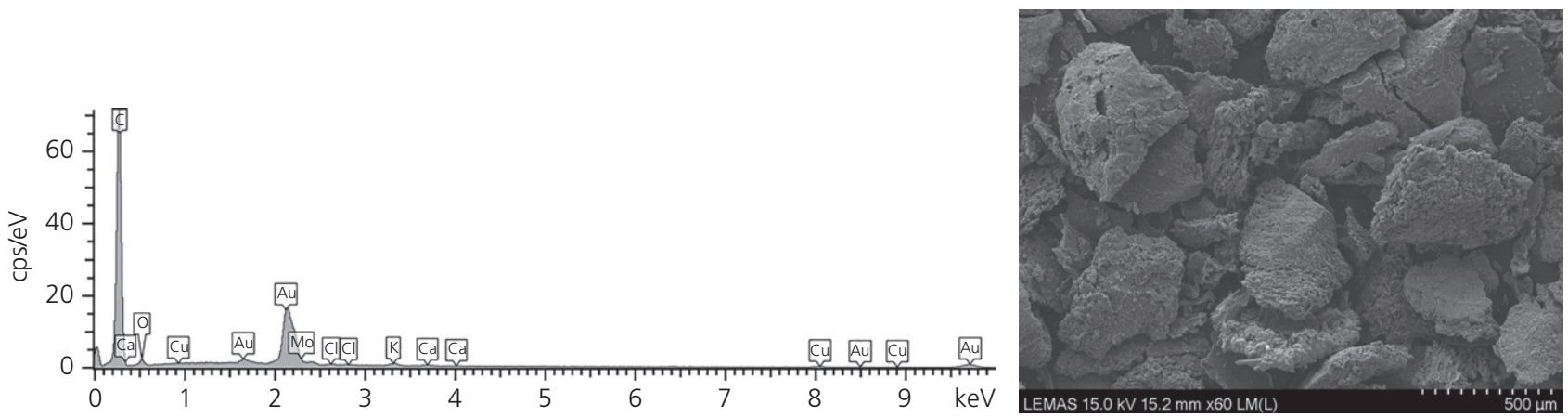

(c)

Figure 2. SEM-EDXS results of waste-derived activated carbons: (a) activated carbon from RDF (AC-R); (b) activated carbon from waste tyre (AC-T); and (C) activated carbon from date seeds (AC-D)

$60 \%$ was found for the commercial $\mathrm{C}-\mathrm{AC} 1$ activated carbon, achieved after the $120 \mathrm{~min}$ test time period. The other commercial activated carbons achieved about 40\% NO removal after $120 \mathrm{~min}$. For the waste-derived activated carbons, the nitrogen oxide concentration after $2 \mathrm{~h}$ adsorption was reduced to $630 \mathrm{ppm}$ with the tyre-derived activated carbon, to $585 \mathrm{ppm}$ for the RDF carbon and to $480 \mathrm{ppm}$ for the biomass (date seeds) activated carbon. The waste-derived activated carbons showed a lower, but still an effective level of NO adsorption, with removal efficiencies of 40,26 and $21 \%$ for the AC-D,
AC-R and AC-T, respectively, at $120 \mathrm{~min}$. It should also be noted that the lower performance of the tyre and RDF activated carbons is linked to the high ash contents of these carbons. Consequently, from Table 2, the actual mass of carbon present in the NO adsorption reactor for the RDF activated carbon $(60.9 \mathrm{wt} \%$ ash) was only $40 \%$ of that used for the commercial activated carbon experiments. Similarly, for the waste tyre activated carbon $(23.9 \mathrm{wt} \%$ ash), there was only $76 \%$ of carbon present compared with the tests using the commercial activated carbons. Therefore, to achieve NO 
Waste-derived activated carbons for

control of nitrogen oxides

Al-Rahbi, Nahil, Wu and Williams adsorption efficiencies comparable to those obtained from commercially available activated carbons, a higher mass of waste-derived activated carbon would be needed.

\subsubsection{Surface area and pore characteristics of activated carbons}

To understand the differing levels of nitrogen oxide removal efficiency found by the different adsorbents, the properties of surface area and porosity of activated carbons were investigated. Pore size for activated carbons are classified into average pore size classes: micropores are of pore width $<2 \mathrm{~nm}$, mesopores of pore width $2-50 \mathrm{~nm}$ and macropores are of pore width $>50 \mathrm{~nm}$. The pore width refers to the distance between the walls of slit-shaped pores or the radius of cylindricalshaped pores.

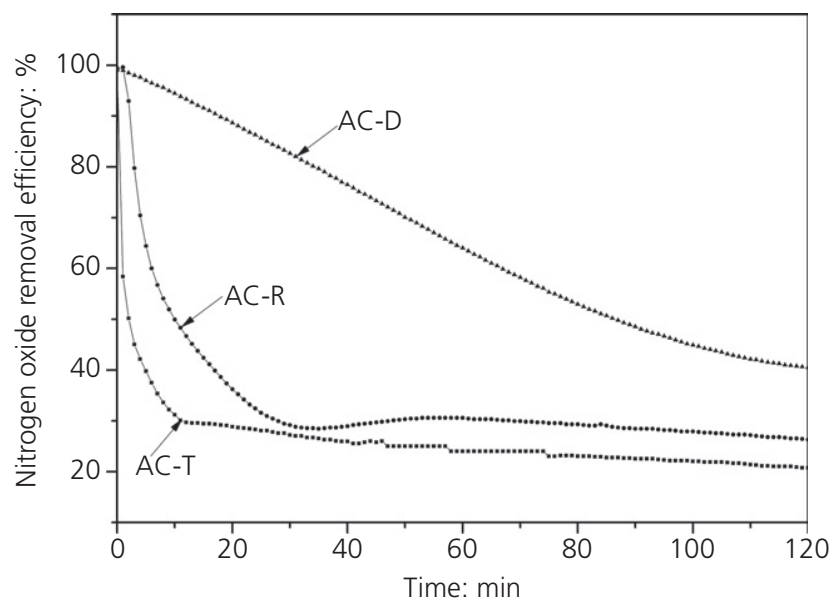

(a)

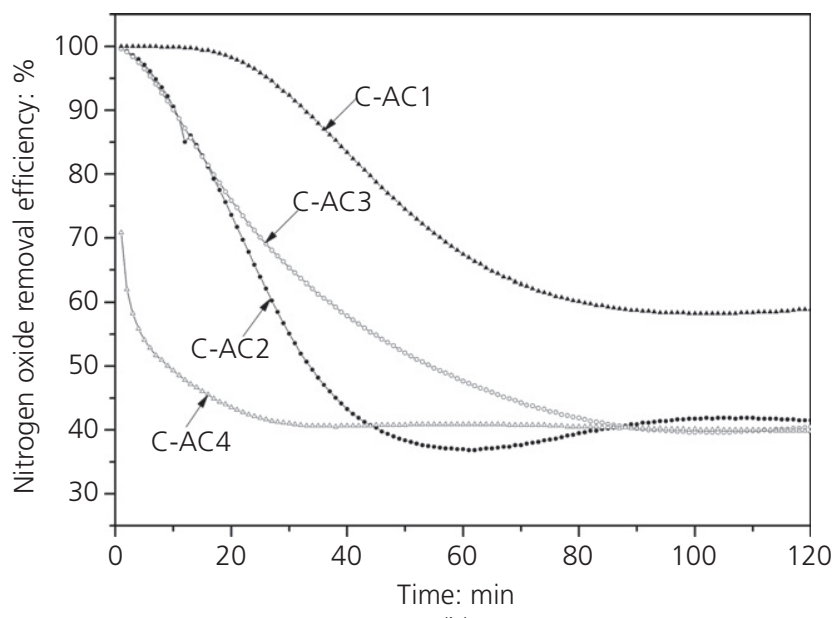

(b)

Figure 3. Nitrogen oxide removal efficiency curves for:

(a) commercial activated carbons and (b) waste-derived activated carbons at $50^{\circ} \mathrm{C}$ adsorption temperature
The nitrogen adsorption-desorption isotherms of the commercial and waste-derived activated carbons are shown in Figures 4(a) and 4(b), respectively. The data suggest that the activated carbons for C-AC1, C-AC2, C-AC3, C-AC4 produced adsorption-desorption isotherms characteristic of type I and type IV isotherms according to the International Union of Pure \& Applied Chemistry (IUPAC) classification (Sing et al., 1985). Therefore, these activated carbons contained both micropores and mesopores. Type I isotherm is characterised by the initial steep portion of the adsorption isotherm at low relative pressures, which represents the filling of the micropores by the adsorbate. The isotherm then reaches a plateau indicating

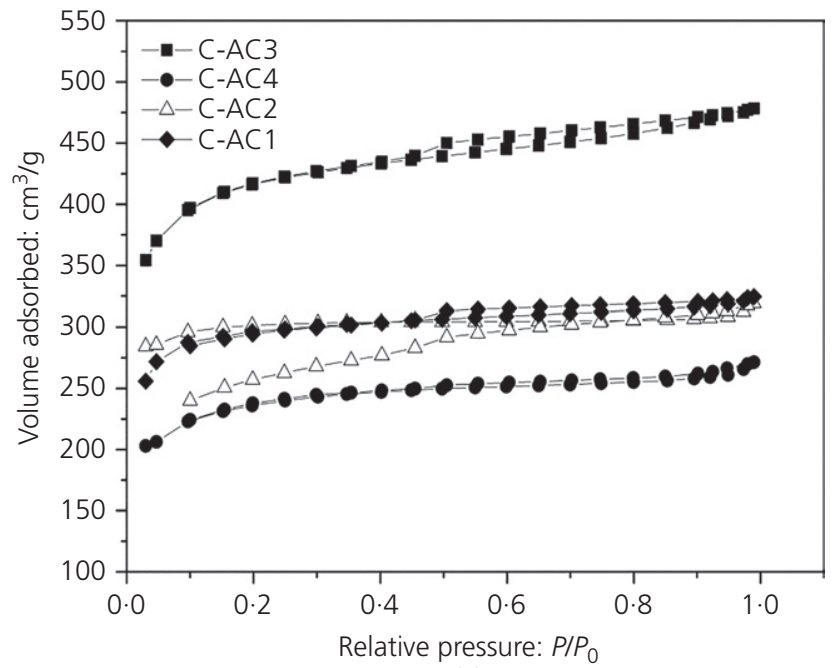

(a)

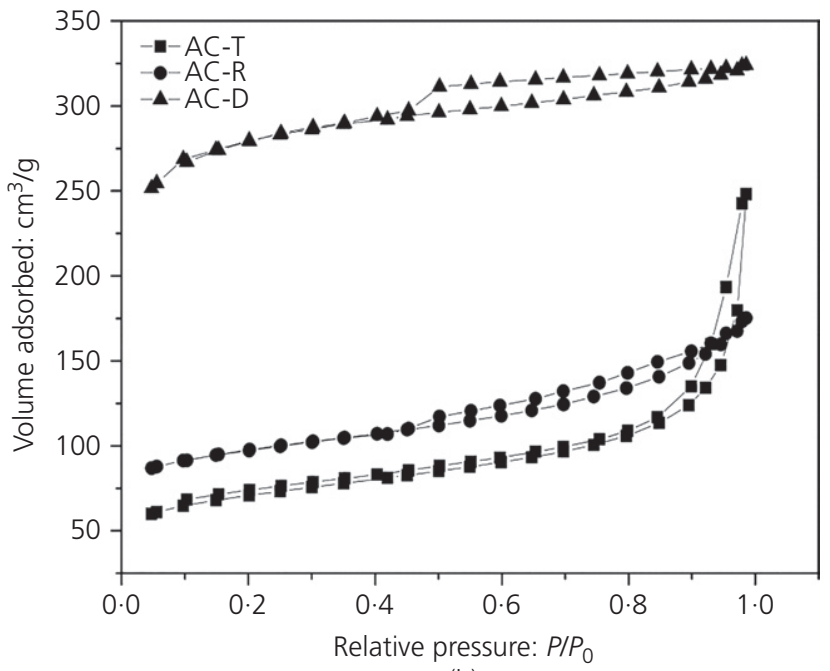

(b)

Figure 4. Nitrogen adsorption desorption isotherms for: (a) the commercial activated carbons and (b) the waste-derived activated carbons 
that the amount adsorbed by a unit mass of activated carbon reaches a limiting value. Type IV isotherm exhibits a significant adsorption-desorption hysteresis loop indicating the filling and emptying of mesopores by capillary condensation. The isotherms obtained for AC-T and AC-R were more similar to type 5 isotherms (Sing et al., 1985), which indicate a more mesoporous type of activated carbon. The amount of nitrogen adsorbed by activated carbons derived from waste is smaller than that of the commercial activated carbons and the knees of their isotherms are more open indicating that they contain more mesopores.

Table 4 shows the surface area, mesopore and micropore volumes of activated carbons. The development of the surface area and porosity characteristics of an activated carbon produced by pyrolysis of the waste raw material followed by steam activation of char is determined by the characteristics of the original raw materials and the process conditions of pyrolysis and activation. The commercial activated carbons had high surface areas, ranging from 558 to $988 \mathrm{~m}^{2} / \mathrm{g}$. In the case of activated carbons produced from waste, surface areas were somewhat lower than the commercial activated carbons at $270 \mathrm{~m}^{2} / \mathrm{g}$ for the AC-T, $340 \mathrm{~m}^{2} / \mathrm{g}$ for the AC-R, but the activated carbon produced from date seeds had a high BET surface area of $867 \mathrm{~m}^{2} / \mathrm{g}$.

In relation to the influence of the surface area and pore size characteristics of the activated carbons on NO adsorption, the BET surface area showed no clear correlation with NO removal efficiency. For example, the highest nitrogen oxide adsorption $(60 \%)$ was achieved with the $\mathrm{C}-\mathrm{AC} 1$ carbon which had the second highest surface area of $944 \mathrm{~m}^{2} / \mathrm{g}$, but C-AC2 and C-AC3 had high surface areas of 912 and $988 \mathrm{~m}^{2} / \mathrm{g}$ but had very different NO adsorption efficiencies. Additionally, date seeds with a surface area of $867 \mathrm{~m}^{2} / \mathrm{g}$ showed a NO removal efficiency similar to $\mathrm{C}-\mathrm{AC} 2$ and $\mathrm{C}-\mathrm{AC} 4$ commercial carbons with a surface area of up to $900 \mathrm{~m}^{2} / \mathrm{g}$. There is also

\begin{tabular}{lccc}
\hline Sample & $\begin{array}{c}\text { Surface } \\
\text { area } \\
S_{\text {BET }}: \mathrm{m}^{2} / \mathrm{g}\end{array}$ & $\begin{array}{c}\text { Micropore } \\
\text { volume } \\
V_{\text {mic }}: \mathrm{cm}^{3} / \mathrm{g}\end{array}$ & $\begin{array}{c}\text { Mesopore } \\
\text { volume } \\
V_{\text {mes }}: \mathrm{cm}^{3} / \mathrm{g}\end{array}$ \\
\hline C-AC1 & 944 & 0.479 & 0.304 \\
C-AC2 & 912 & 0.466 & 0.109 \\
C-AC3 & 988 & 0.510 & 0.324 \\
C-AC4 & 750 & 0.350 & 0.145 \\
AC-T (tyre) & 270 & 0.214 & 0.784 \\
AC-R (RDF) & 340 & 0.223 & 0.620 \\
AC-D (biomass) & 867 & 0.478 & 0.203
\end{tabular}

Table 4. Surface area and pore size characteristics of commercial and waste-derived activated carbons disagreement in the literature regarding the influence of surface area and porosity on the rate of nitrogen oxide reduction on a carbon surface. Several authors (Guo et al., 2001; Ruiz Machado and Hall, 1998) have considered that the rate of NO adsorption is proportional to the internal surface area of the char. However, Neathery et al. (1997) observed that the NO adsorption capacity of the studied activated carbons was not directly related to their surface areas and micropore volumes. The same conclusion was derived by Guo et al. (2001) and Ruiz Machado and Hall (1998). Other overriding factors that may influence NO adsorption over the carbon surface area are the size of the molecule being adsorbed such that the pollutant cannot enter the micropores of the carbon and the surface chemistry of the carbon which may not be conducive to nitrogen oxide adsorption (Mohan and Pittman, 2006).

The pore size characteristics (Table 4) of the commercial carbons showed that C-AC1, C-AC2, C-AC3 AC-D contained a mixture of micropores and mesopores and C-AC4 was mainly microporous and the tyre (AC-T) and RDF activated carbons (AC-R) were mainly mesoporous.

Figures 5(a) and 5(b) shows the pore size distribution of the commercial adsorbents and activated carbon produced from the wastes, respectively, as calculated by the DFT method. For the adsorbents produced in this study, analysis of pore size data presented in Table 4 and Figure 5, indicate that NO adsorption could potentially depend, on the one hand, on the origin of the carbon and, on the other hand, on the pore volume and pore size distribution. The lower removal efficiency of activated carbons produced from waste tyre and RDF compared with those of commercial carbons or date seeds is largely due to the differences in porous structure. The pores of the commercial activated carbons and biomass date seeds are mostly located in the micropore range of 1-2 nm, while the activated carbons produced from RDF and tyre have a much greater number of pores with diameters in the range of $2-10 \mathrm{~nm}$, particularly many pores $>4 \mathrm{~nm}$. Pores of these sizes are probably unsuitable for effective $\mathrm{NO}$ adsorption, since the kinetic diameter of $\mathrm{NO}$ is $0.317 \mathrm{~nm}$, suggesting microporous activated carbons would be more suitable for NO adsorption. The prevalence of mesopores in the tyre- and the RDFderived carbons seems to reduce the efficiency of the product activated carbon to capture NO. Carbons with pore diameters of $1.1 \mathrm{~nm}$ have been found to have a much higher capacity than those with pore diameters larger than $1 \cdot 1 \mathrm{~nm}$ (Neathery et al., 1997).

To further study the influence of surface area and porosity on NO adsorption, one of the waste materials (waste tyre) was activated to different degrees of carbon burn off, to prepare activated carbons with different surface area and pore size 


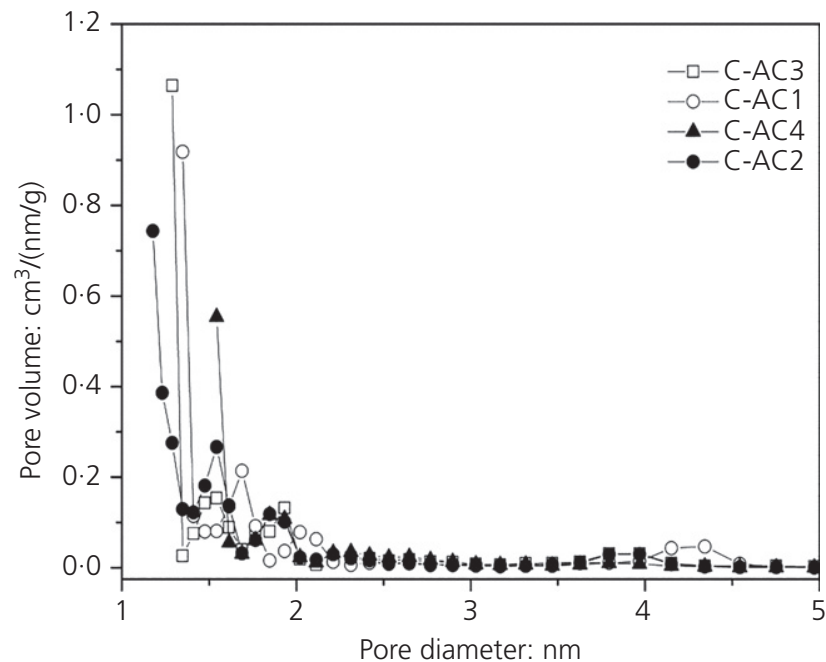

(a)

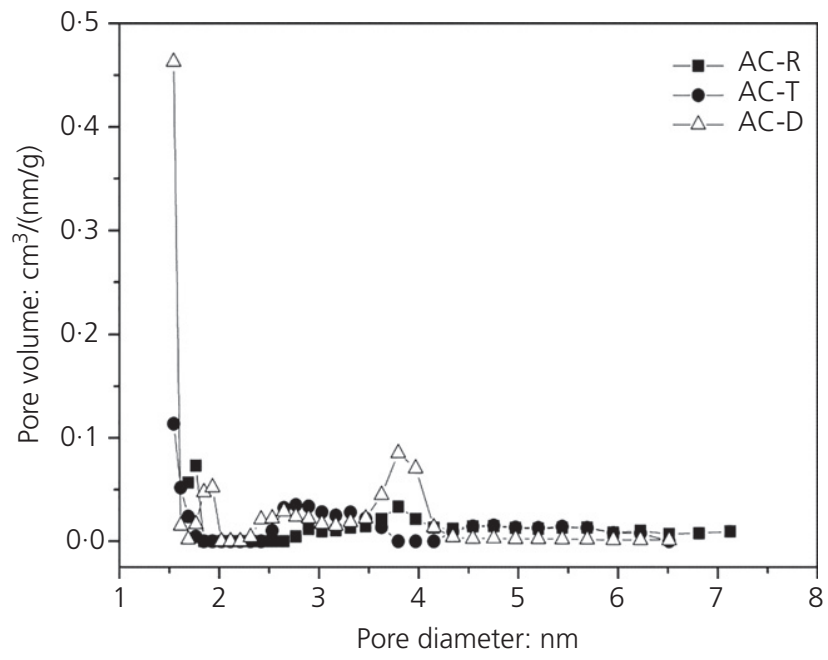

(b)

Figure 5. Pore size distribution for: (a) commercial activated carbons and (b) waste-derived activated carbons characteristics together with the NO adsorption efficiency after $120 \mathrm{~min}$ of operation (Table 5). The data presented in Table 5 show that increasing the activation time led to an increase in the BET surface area $\left(S_{\mathrm{BET}}\right)$ and micropore volume $\left(V_{\text {mic }}\right)$, which is accompanied by a proportional increase in NO removal. This suggests that the porous texture has a role in determining NO capture by the studied carbons. However, there appeared to be no correlation with the mesoporosity of the tyre-derived activated carbons and $\mathrm{NO}$ removal efficiency.

\subsubsection{Acid-base properties}

The surface chemistry of the product activated carbons may also influence the uptake of NO. The chemical structure of activated carbons is associated with heteroatoms (hydrogen, oxygen, nitrogen and sulfur) which are bonded at the edges of aromatic carbon sheets or to carbon atoms within the carbon matrix forming various surface functional groups which can be acidic, basic or neutral (Guo and Lua, 1999). These functional groups are responsible for the uptake of pollutants. The commercial and the waste-derived activated carbons were therefore analysed by Boehm titration to determine the concentration of basic and acidic chemical groups on the carbon surface. The results are shown in Table 6. For the commercial

\begin{tabular}{lrccc}
\hline Sample & $\mathrm{pH}$ & $\begin{array}{c}\text { Basic } \\
\text { groups: } \\
\mathrm{mmol} / \mathrm{g}\end{array}$ & $\begin{array}{c}\text { Acidic } \\
\text { groups: } \\
\mathrm{mmol} / \mathrm{g}\end{array}$ & $\begin{array}{c}\text { Total content } \\
\text { of surface } \\
\text { oxides }\end{array}$ \\
\hline C-AC1 & 9.52 & 1.22 & 0.05 & 1.27 \\
C-AC2 & 9.20 & 1.17 & 0.13 & 1.29 \\
C-AC3 & 9.24 & 0.66 & 0.02 & 0.67 \\
C-AC4 & 7.58 & 0.69 & 0.00 & 0.68 \\
AC-R (RDF) & 10.67 & 2.65 & 0.00 & 2.65 \\
AC-T (tyre) & 8.11 & 0.51 & 0.30 & 0.82 \\
AC-D (biomass) & 7.53 & 0.71 & 0.00 & 0.71
\end{tabular}

Table 6. Acid and base properties of activated carbons

\begin{tabular}{lccccc}
\hline Sample & $\begin{array}{c}\text { Activation } \\
\text { time: } \min \end{array}$ & $\begin{array}{c}\text { Surface area } \\
S_{\text {BET }}: \mathrm{m}^{2} / \mathrm{g}\end{array}$ & $\begin{array}{c}\text { Mesopore volume } \\
V_{\text {mes }}: \mathrm{cm}^{3} / \mathrm{g}\end{array}$ & $\begin{array}{c}\text { Micropore volume } \\
V_{\text {mic }}: \mathrm{cm}^{3} / \mathrm{g}\end{array}$ & $\begin{array}{r}\text { Nitrogen } \\
\text { oxide: \% }\end{array}$ \\
\hline AC-T (tyre) & 45 & 88 & 0.61 & $0 \cdot 09$ & 9 \\
AC-T (tyre) & 90 & 70 & 0.54 & 0.08 & 7 \\
AC-T (tyre) & 180 & 270 & 0.70 & 0.20 & 23
\end{tabular}

Table 5. Influence of surface area $\left(S_{\mathrm{BET}}\right)$, mesopore volume $\left(V_{\text {mes }}\right)$ and micropore volume $\left(V_{\text {mic }}\right)$ of the tyre-derived activated carbons on nitrogen oxide removal efficiency at $120 \mathrm{~min}$ 
carbons, the content of the basic surface groups varied in the range of $0.66-1.22 \mathrm{mmol} / \mathrm{g}$, while for the RDF waste-derived activated carbon, the content of basic surface groups was almost double $(2.65 \mathrm{mmol} / \mathrm{g})$. The very high content of basic groups with RDF could be due to presence of the high mineral components and metal compounds found in the raw precursor material (Table 1) and also as shown by the SEM-EDXS analysis of waste-derived activated carbons (Figure 2).

$\mathrm{Hu}$ et al. (2011) and Nowicki and Pietrzak (2011) found that activated carbons with the highest content of basic groups and the lowest content of acidic groups had the highest $\mathrm{NO}_{x}$ sorption capacity. A comparison of the acidic and basic groups on the activated carbons (Table 6) with the NO removal data shown in Figure 3 showed that the commercial activated carbon with the highest basic groups $\mathrm{C}-\mathrm{AC}-1$ had the highest NO removal efficiency. $\mathrm{C}-\mathrm{AC} 1$ and $\mathrm{C}-\mathrm{AC} 2$ have a similar amount of basic groups but $\mathrm{C}-\mathrm{AC} 2$ has a higher amount of acidic groups which could be the reason for the lower NO removal efficiency of C-AC2. The inhibitory effect of acidic groups to the nitrogen oxide adsorption capacity of carbons has been reported in the literature (Nowicki and Pietrzak, 2011). For the activated carbon produced from waste, the AC-R had the highest concentration of basic groups but showed no significant influence on NO removal compared with the other activated carbons, suggesting that other inhibitory factors related to metal content or pore structure influence nitrogen oxide adsorption for the RDF activated carbon.

\subsection{Influence of temperature and nitrogen oxide concentration on nitrogen oxide adsorption}

The influence of the process parameters of adsorption temperature and NO gas concentration on the adsorption of nitrogen oxide was examined for tyre- and biomass-derived activated carbons. The RDF activated carbon was not further investigated due to the high ash content of the product carbon. Table 7 shows the influence of activated carbon temperature using the NO adsorption reactor (Figure 1(c)). Adsorption experiments were carried out at temperatures of 25, 50 and $100^{\circ} \mathrm{C}$ and fixed $\mathrm{NO}$ concentration of $800 \mathrm{ppm}$ and oxygen concentration of $5 \%$. Both the tyre-derived carbon and the biomass-derived carbon showed a decrease in NO removal efficiency as the adsorption temperature was increased. At low temperature, physisorption of NO takes place on the carbon surface which means that activated carbon acts as a medium for adsorbing the reactants and not as a catalyst (chemisorption), this will lead to a decrease in NO conversion with increasing temperature. Guo et al. (2001) also reported a decrease in the adsorption of NO with an increase in temperature from 30 to $100^{\circ} \mathrm{C}$ for $\mathrm{NO}$ adsorption onto activated carbon fibres.
Nitrogen oxide adsorption: \%

\begin{tabular}{lcr}
\cline { 2 - 3 } Parameter & AC-T (tyre) & AC-D (bio \\
\hline Adsorption temperature: ${ }^{\circ} \mathrm{C}$ & 65 \\
25 & 37 & 41 \\
50 & 23 & 12 \\
100 & 6 & \\
Nitrogen oxide concentration (ppm) (for an adsorption \\
temperature of $25^{\circ} \mathrm{C}$ ) & & 80 \\
200 & 27 & 77 \\
400 & 31 & 65 \\
800 & 35 &
\end{tabular}

Table 7. Influence of process parameters on nitrogen oxide removal efficiency at 120 min for tyre-derived (AC-T) and biomass (AC-D)-derived activated carbons

The NO removal efficiency of carbon will also depend on the nitrogen oxide concentration in the flue gas. The effect of varying the inlet flue gas nitrogen oxide concentration on the adsorption capacity of activated carbons produced from waste tyre and biomass date seeds was assessed. Experiments were carried out with NO inlet concentration of 200, 400, $800 \mathrm{ppm}$ in the flue gas and with a fixed oxygen concentration of $5 \%$ at $25^{\circ} \mathrm{C}$. The effect of increasing the NO concentration did not reveal the same trend for both carbons; this could be due to the difference in the surface chemistry of the adsorbents. For the date seeds, there was a substantial increase in adsorption as the NO was increased from 200 to $400 \mathrm{ppm}$ and then declined at $800 \mathrm{ppm}$ In the case of waste tyre, NO removal efficiency increased with increasing NO concentration (Table 7). A similar behaviour was observed by others (Guo et al., 2001; Klose and Rincón, 2007; Mochida et al., 2000). For example, Guo et al. (2001) investigated the influence of NO concentration on NO adsorption with activated carbon and reported a $69 \% \mathrm{NO}$ adsorption capacity at $600 \mathrm{ppm}$ NO concentration, reducing to $65 \%$ at $200 \mathrm{ppm}$ but reducing markedly to $40 \%$ at $50 \mathrm{ppm}$.

\section{Conclusions}

Adsorption of $\mathrm{NO}$ at low temperatures was studied using activated carbon produced from waste materials. Different commercial carbons with different porous texture and surface chemistry were used for comparison. The porous structure and surface chemistry of the studied adsorbents were analysed and compared with the nitrogen oxide removal efficiency of carbons. From the presented results and analysis, it can be concluded that the micropore size and the pore width play an important role in determining the efficiency of activated carbons for NO capture, but less so for surface 
area. The differences in performance of the activated carbons could also be attributed to the influence of porous texture and surface chemistry. The waste-derived activated carbons had NO removal efficiencies of 40,26 and $21 \%$ for the carbons derived from date seeds, RDF and waste tyres, respectively, at $50^{\circ} \mathrm{C}$ adsorption temperature. Commercially produced activated carbons had NO removal efficiencies of between 40 and $60 \%$. Therefore, although the waste-derived activated carbons were somewhat less effective than commercially produced carbons they still showed a high and effective level of NO removal. In addition, the use of waste materials for the minimisation of a problematic pollutant is a novel reuse of resources.

\section{Acknowledgements}

The support extended for the study by the Government of Oman through a scholarship to one of the authors (A.S.S.A.) is acknowledged.

\section{REFERENCES}

Ahmed SN, Stencel JM, Derbyshire FJ and Baldwin RM (1993) Activated carbons for the removal of nitric oxide. Fuel Processing Technology 34(2): 123-136.

Amalraj A and Piu SA (2013) Removal of selected basic dyes using activated carbon from tannery wastes. Separation Science and Technology 49(1): 90-100.

Azambre B, Zenboury L, Koch A and Weber JV (2009) Adsorption and desorption of $\mathrm{NO}_{x}$ on commercial ceriazirconia $\left(\mathrm{Ce}_{x} \mathrm{Zr}_{1}-{ }_{x} \mathrm{O}_{2}\right)$ mixed oxides: a combined TGA, TPD-MS, and DRIFTS study. Journal of Physical Chemistry C 113(30): 13287-13299.

Bashkova S and Bandosz TJ (2009) The effects of urea modification and heat treatment on the process of $\mathrm{NO}_{2}$ removal by wood-based activated carbon. Journal of Colloid and Interface Science 333(1): 97-103.

Belhachemi M, Jequirim M, Limousy L and Addoun F (2014) Comparison of $\mathrm{NO}_{2}$ removal using date pits activated carbon and modified commercialized activated carbon via different preparation methods: effect of porosity and surface chemistry. Chemical Engineering Journal 253(3): 121-129.

Buah WK and Williams PT (2010) Activated carbons prepared from refuse derived fuel and their gold adsorption characteristics. Environmental Technology 31(2): 125-137.

Claudino A, Soares JL, Moreira RFP and Jose HJ (2004) Adsorption equilibrium and breakthrough analysis for $\mathrm{NO}$ adsorption on activated carbons at low temperatures. Carbon 42(8-9): 1483-1490.

Degroot WF, Osterheld TH and Richards GN (1991) Chemisorption of oxygen and of nitric oxide on cellulosic chars. Carbon 29(2): 185-195.

El-Kady AA, Ghafar HHA, Ibrahim MBM and Abdel-Wahhab MA (2013) Utilization of activated carbon prepared from agricultural waste for the removal of organophosphorous pesticide from aqueous media. Desalination and Water Treatment 51(37-39): 7276-7285.

Gil RR, Ruiz B, Lozano MS, Martin MJ and Fuente E (2014) VOCs removal by adsorption onto activated carbons from biocollagenic wastes of vegetable tanning. Chemical Engineering Journal 245: 80-88.

Gómez-García MA, Pitchon V and Kiennemann A (2005) Pollution by nitrogen oxides: an approach to $\mathrm{NO}_{x}$ abatement by using sorbing catalytic materials. Environment International 31(3): 445-467.

Gundogdu A, Duran C, Senturk HB et al. (2013) Physicochemical characteristics of a novel activated carbon produced from tea industry waste. Journal of Analytical and Applied Pyrolysis 104: 249-259.

Guo J and Lua AC (1999) Effect of surface chemistry on gasphase adsorption byactivated carbon prepared from oilpalm stone with pre-impregnation. Separation and Purification Technology 18(1): 47-55.

Guo Z, Xie Y, Hong I and Kim J (2001) Catalytic oxidation of $\mathrm{NO}$ to $\mathrm{NO}_{2}$ on activated carbon. Energy Conversion and Management 42(15-17): 2005-2018.

Gupta VK, Nayak A, Agarwal S and Tyagi I (2014) Potential of activated carbon from waste rubber tire for the adsorption of phenolics: effect of pre-treatment conditions. Journal of Colloid and Interface Science 417: 420-430.

Hajizadeh Y, Onwudili JA and Williams PT (2011) Removal potential of toxic 2378-substituted PCDD/F from incinerator flue gases by waste-derived activated carbons. Waste Management 31(6): 1194-1201.

Hu H, Lu X, Wang F et al. (2011) Activated carbon based selective purification of medical grade NO starting from arc discharge method. Carbon 49(7): 2197-2205.

Illan-Gomez MJ, Linares-Solano A, Salinas-Martinez C and Calo JM (1993) Nitrogen oxide (NO) reduction by activated carbons. 1 . The role of carbon porosity and surface area. Energy and Fuels 7(1): 146-154.

Illingworth J, Williams PT and Rand B (2012) Novel activated carbon fibre matting from biomass fibre waste. Waste and Resource Management 165: 123-132.

Kaneko K, Nakahigashi Y and Nagata K (1988) Microporosity and adsorption characteristics against $\mathrm{NO}, \mathrm{SO}_{2}$, and $\mathrm{NH}_{3}$ of pitch-based activated carbon fibers. Carbon 26(3): 327-332.

Kante K, Deliyanni E and Bandosz TJ (2009) Interactions of $\mathrm{NO}_{2}$ with activated carbons modified with cerium, lanthanum and sodium chlorides. Journal of Hazardous Materials 165(1-3): 704-713.

Klose W and Rincón S (2007) Adsorption and reaction of NO on activated carbon in the presence of oxygen and water vapour. Fuel 86(1-2): 203-209.

Lee YW, Park JW, Jun SJ, Choi DK and Yie JE (2004) $\mathrm{NO}_{x}$ adsorption-temperature programmed desorption and surface molecular ions distribution by activated carbon with chemical modification. Carbon 42(1): 59-69. 
Levasseur B, Ebrahim AM and Bandosz TJ (2012) Mesoporous silica SBA-15 modified with copper as an efficient $\mathrm{NO}_{2}$ adsorbent at ambient conditions. Journal of Colloid and Interface Science 377(1): 347-354.

Liu X, Zhang W and Zhang Z (2014) Preparation and characteristics of activated carbon from waste fiberboard and its use for adsorption of $\mathrm{Cu}(\mathrm{II})$. Materials Letters 116: 304-306.

Lopez DRB, Sepulveda-Escribano A, Rodriguez-Reinoso F and Mondragon F (2007) Low-temperature catalytic adsorption of NO on activated carbon materials. Langmuir 23(24): 12131-12137.

Mochida I, Kisamori S, Hironaka M et al. (1994) Oxidation of $\mathrm{NO}$ into $\mathrm{NO}_{2}$ over active carbon fibers. Energy and Fuels 8(6): 1341-1344.

Mochida I, Shirhama N, Kawano S et al. (2000) NO oxidation over activated carbon fiber (ACF). Part 1. Extended kinetics over a pitch based ACF of very large surface area. Fuel 79(14): 1713-1723.

Mohan D and Pittman CU (2006) Activated carbons and low cost adsorbents for remediation of tri- and hexavalent chromium from water. Journal of Hazardous Materials 137(2): 762-811.

Nahil MA and Williams PT (2010) Activated carbons from acrylic textile waste. Journal of Analytical and Applied Pyrolysis 89(1): 51-59.

Neathery JK, Rubel AM and Stencel JM (1997) Uptake of $\mathrm{NO}_{x}$ by activated carbons: bench-scale and pilot-plant testing. Carbon 35(9): 1321-1327.

Nowicki P and Pietrzak R (2011) Effect of ammoxidation of activated carbons obtained from sub-bituminous coal on their $\mathrm{NO}_{2}$ sorption capacity under dry conditions. Chemical Engineering Journal 166(3): 1039-1043.
Rathore RS, Srivastava DK, Agarwal AK and Verma N (2010) Development of surface functionalized activated carbon fiber for control of NO and particulate matter. Journal of Hazardous Materials 173(1-3): 211-222.

Rubio B and Izquerido MT (2013) Nitric oxide removal from flue gases by carbon-enriched coal fly ash. Environmental Research, Engineering and Management 1(63): 5-16.

Ruiz Machado WA and Hall JP (1998) Effects of porosity on carbon reactivity in $\mathrm{NO}$ and $\mathrm{O}_{2}$. Energy and Fuels 12(5): 958-962.

Shirahama N, Moon SH, Cho IKH et al. (2002) Mechanistic study on adsorption and reduction of $\mathrm{NO}_{2}$ over activated carbon fibers. Carbon 40(14): 2605-2611.

Sing KSW, Everett DH, Haul RAW et al. (1985) Reporting physisorption data for gas solid systems with special reference to the determination of surface area and porosity. Pure and Applied Chemistry 57(4): 603-619.

Sousa JPS, Pereira MFR and Figueiredo JL (2013) Modified activated carbon as catalyst for NO oxidation. Fuel Processing Technology 106: 727-733.

Teng $\mathrm{H}$ and Suuberg EM (1993) Chemisorption of nitric oxide on char. 1. Reversible nitric oxide sorption. Journal of Physical Chemistry 97(2): 478-483.

Xu XH, Shi Y, Liu H, Wang HP and Chang SG (2003) Method for the control of $\mathrm{NO}_{x}$ emissions in long-range space travel. Energy and Fuels 17(5): 1303-1310.

Yang J, Mestl G, Herein D, Schlogl R and Find J (2000) Reaction of NO with carbonaceous materials: 2. Effect of oxygen on the reaction of $\mathrm{NO}$ with ashless carbon black. Carbon 38(5): 729-740.

Zhang WJ, Rabei S, Bagreev A, Zhuang MS and Rasoul IF (2008) Study of NO adsorption on activated carbons. Applied Catalysis B: Environmental 83(1-2): 63-71.

\section{WHAT DO YOU THINK?}

To discuss this paper, please email up to 500 words to the editor at journals@ice.org.uk. Your contribution will be forwarded to the author(s) for a reply and, if considered appropriate by the editorial panel, will be published as discussion in a future issue of the journal.

Proceedings journals rely entirely on contributions sent in by civil engineering professionals, academics and students. Papers should be 2000-5000 words long (briefing papers should be 1000-2000 words long), with adequate illustrations and references. You can submit your paper online via www.icevirtuallibrary.com/content/journals, where you will also find detailed author guidelines. 